\title{
AC 2007-1650: COMMUNITY AND FAMILY MATH NIGHTS AS A VEHICLE FOR MATHEMATICS SUCCESS
}

\section{Laura Bottomley, North Carolina State University}

LAURA J. BOTTOMLEY is the Director of the Women in Engineering and Outreach Programs at North Carolina State University and a partner of Science Surround, a science education business for children. She is the immediate past chair of the K-12 Division of ASEE. Dr. Bottomley received her Ph.D. in electrical engineering from North Carolina State University in 1992, and her MSEE and BSEE from Virginia Tech in 1984 and 1985, respectively. She has worked at AT\&T Bell Labs and Duke University.

\section{Elizabeth Parry, North Carolina State University}

ELIZABETH A. PARRY is currently the Project Director of RAMP-UP, a K12 math outreach program funded by the GE and the National Science Foundations. She obtained her BS degree in engineering management with a minor in mechanical engineering from the University of Missouri-Rolla in 1983. After over 10 years with IBM, she resigned to concentrate on raising her children, partnering in a science education business (Science Surround) and consulting for NC State University's College of Engineering.

\section{Karen Hollebrands, North Carolina State University}

KAREN HOLLEBRANDS is an Assistant Professor of Mathematics Education at North Carolina State University. She completed her Ph.D. in Mathematics Education at The Pennsylvania State University. Prior to attending Penn State, Dr. Hollebrands taught high school mathematics in New York and North Carolina. She is currently serving as the editor of the Technology Tips column in the Mathematics Teacher. 


\title{
Community and Family Math Nights as a Vehicle for Mathematics Success
}

\begin{abstract}
$\underline{\text { Abstract }}$
Mathematics is an important basis for many aspects of the engineering curriculum, and, whether we like it or not, can also be a discouraging factor for students who would make excellent engineers. Many students whose parents did not themselves experience math success in school will be similarly burdened by a lack of support and understanding at home. In addition, mathematics curricula have changed and continue to change from those of the years that babyboomers were in elementary and middle school. Many parents are not well equipped to support their children in math classes, and mathematics attitudes and impressions are formed early, with the student (especially those from underrepresented groups) following the parents' lead.

This paper will describe the creation, implementation and assessment of successful community and family math nights, which to date have served over 3000 people. These events bring parents, students and teachers together with university engineering students and teachers to experience inquiry-oriented math lessons that reinforce both basic and critical thinking skills. The activities are fun for the kids and instructive for the parents and are meant to be done together with simple supplies. Parent workshops as well as detailed information on how to help their children solve problems and apply math are provided. Family Math Nights are designed and implemented to alleviate math anxiety, in part by having university students and professors working with the families as they explore the mathematics curriculum in grades K-8. At many community math nights, a large percentage of the parents in attendance had never before attended a school event.
\end{abstract}

\section{$\underline{\text { Introduction }}$}

Mathematics is a well known and accepted 'gatekeeper' subject for science, technology, engineering and mathematics (STEM) professionals. George Gagnon notes on his New Horizons for Learning web site that "less that a third of students in urban schools are learning enough math to complete STEM majors in college, although only a third of these successful students actually enroll in these majors." "The remaining two thirds of these students either self select themselves out of more advanced courses in math and science or are lost to STEM careers or school. Identification of mathematics as a subject primarily for the gifted goes back to Plato, who said "those who have a natural talent for calculation are generally quick-witted at every other kind of knowledge." "2 Unfortunately many factors other than math aptitude and general intelligence play a significant role in a student's continued success in math as well as their propensity to enroll in university preparation math courses in high school. Different learning styles, ability grouping and tracking and support at home are but a few of the major obstacles to math success in K-12 education, particularly in grades 6-12. The latter is compounded by the fact that today's parents were taught math in a completely different way than their children are being taught, and that 
parents, especially those with children in secondary school, see themselves as much less able to help their children with math concepts and homework (see figure 2).

Research, ours and others', also indicates that a child's self esteem and confidence in math is directly related to parent perceptions and expectations. The student's own achievement record or the attitudes of any single teacher do not have the same degree of influence. One researcher states that, "a student's initial competence in mathematics and science grows out of family practices." 3

Parent advocacy and education groups have deemed that "parent involvement" is a necessary component of student success 4 . The definition of "parent involvement," however, varies from state to state, town to town and even school to school within a town. The National Parent Teacher Association defines parent involvement as "the participation of parents in every facet of children's education and development from birth to adulthood, recognizing that parents are the primary influence in children's lives." (http://www.ctpta.org/parenting/parent_involvement.htm). The Association for Supervision and Curriculum Development web site says, "Family math helps students improve their skill by engaging in mathematical exercises with their parents at home, schools or elsewhere in local communities." 5 o, given the confluence of both mathematics as a gatekeeper subject and parents as key to their children's academic success, it follows that efforts to involve and engage parents in mathematics instruction and learning will be very beneficial.

\section{$\underline{\text { History }}$}

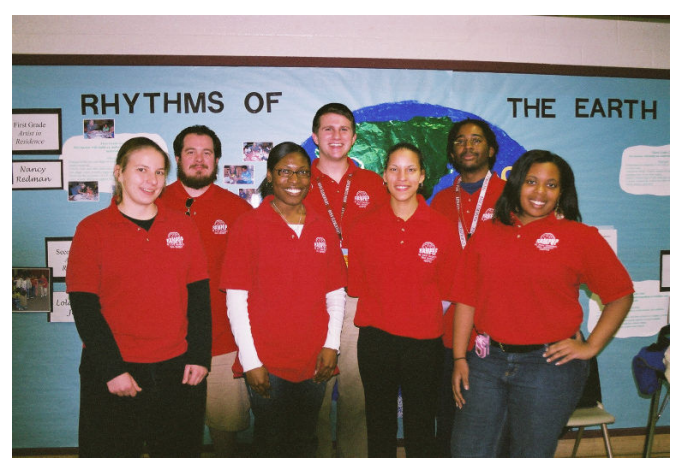

The elementary Family Math Night project was developed by RAMP-UP (Recognizing Accelerated Math Potential in Underrepresented People) personnel at North Carolina State University. RAMP-UP, a five year, $\$ 2.5$ million grant funded by the National Science and GE Foundations, focuses on increasing the number and diversity of K-12 students who take and succeed in algebra by $8^{\text {th }} / 9^{\text {th }}$ grade and calculus by $12^{\text {th }}$. RAMPUP fellows are undergraduate engineers, scientists, mathematicians and pre-service secondary math education students partnered with nearly $70 \mathrm{~K}-12$ teachers at eight local schools. The undergraduates are themselves supervised by five graduate students in engineering.

The genesis of the Family Math Night was a natural outgrowth of the grant's goals to increase the participation of students from underrepresented groups in advanced math. The program's goal in elementary school is to positively influence alternative methods of recommendation for advanced math classes. While increasing the pool remains a goal in all grade levels we work in, in middle and high school the program's goals shift somewhat to supporting and sustaining students in mathematics by demonstrating through inquiry based activities the application of the math theory they are learning. 
Now in the third year of the program, RAMP-UP project leaders have utilized the results of constituent surveys taken the first two years to tailor the program. Math Night is an outgrowth of data collected on parent surveys. These surveys asked about parental backgrounds in math, including level of math taken in high school, comfort in math, perceived aptitude in the subject and of particular interest, the grade level at which they began to feel unable to help their children with math homework. Overwhelmingly, the parents cited 'middle school' (starting in sixth grade in our state) as the time when they no longer felt comfortable with helping their children solve math homework problems. Some of the survey results are summarized in the table below.

- All parents report that they rarely communicate with their child's teacher.

- Parents at all schools report that they are only slightly familiar with their child's math program.

- For all schools, parents report that a teacher was their strongest math influence with parent tied for next highest.

- Almost all parents report their first math recollections in elementary school.

- Parents in elementary school report liking math, but middle and high school parents report less positive feelings. This warrants further study; one hypothesis is that this is related to their feeling of inadequacy in helping their children in those grade levels

Table 1: Parent math survey respondent demographics

\begin{tabular}{|c|c|c|c|c|c|}
\hline \multicolumn{2}{|c|}{ Ethnicity of respondents } & \multicolumn{2}{c|}{ Grade completion of respondents } & \multicolumn{2}{c|}{ Gender of respondents } \\
\hline $\begin{array}{c}\text { African } \\
\text { American }\end{array}$ & $31 \%$ & Middle School & $0 \%$ & Male & $24 \%$ \\
\hline Asian & $8 \%$ & High School & $18 \%$ & Female & $76 \%$ \\
\hline Caucasian & $53 \%$ & $\begin{array}{c}\text { Associate's } \\
\text { Degree }\end{array}$ & $16 \%$ & & \\
\hline Hispanic & $2 \%$ & $\begin{array}{c}\text { Bachelor's } \\
\text { Degree }\end{array}$ & $34 \%$ & & \\
\hline Other & $3 \%$ & Graduate Degree & $31 \%$ & & \\
\hline No Response & $3 \%$ & No Response & $1 \%$ & & \\
\hline
\end{tabular}

Figure 1: Parent survey results for math influence, $N=143$

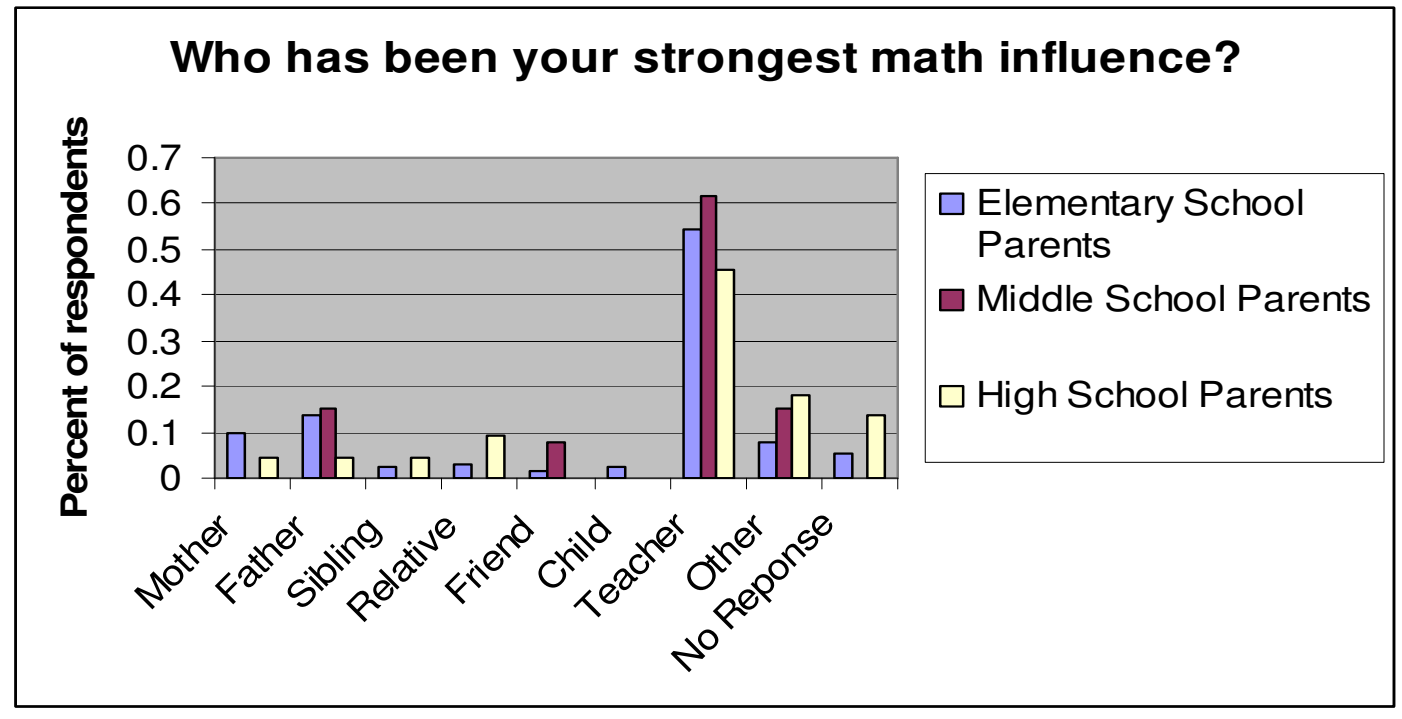


Figure 2: Parent survey results about comfort helping children with math, $N=143$

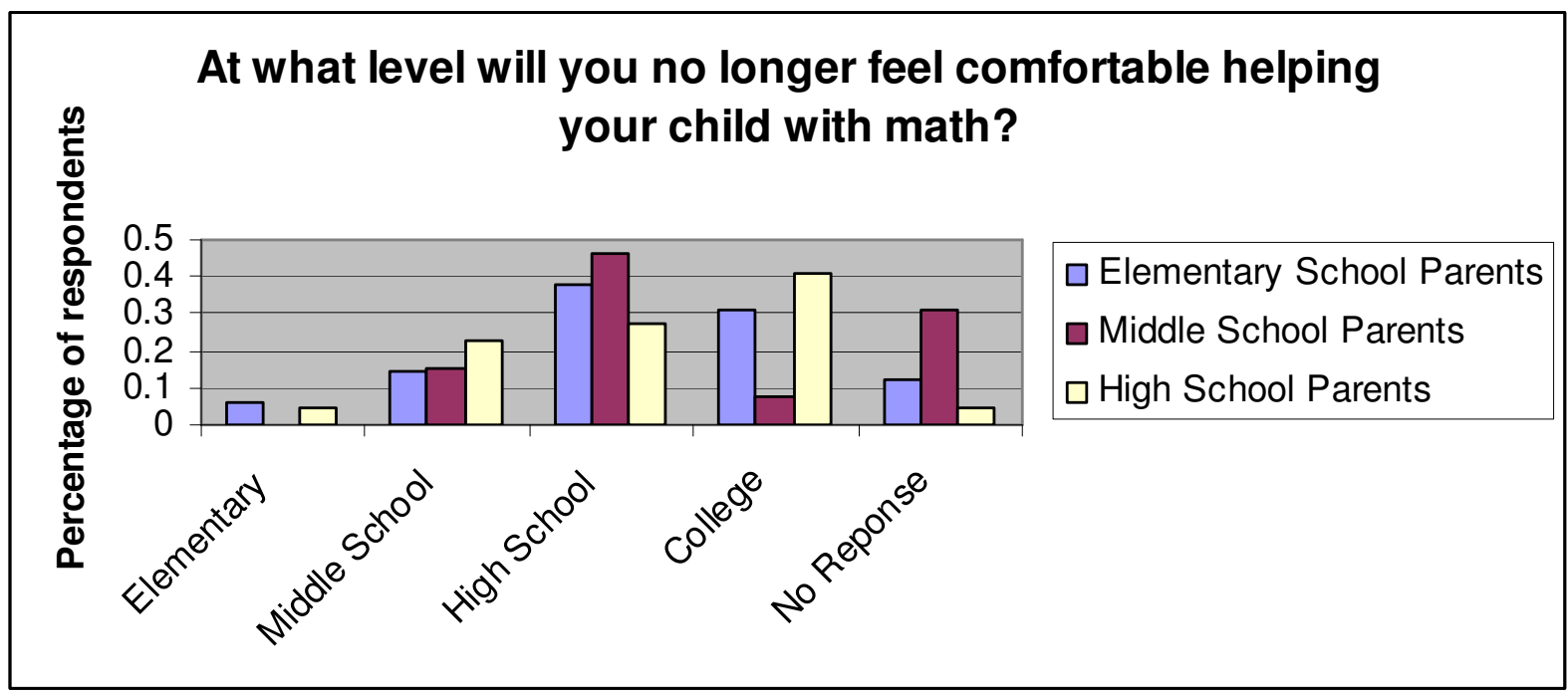

Figure 3: Parent survey results about math feelings, $N=143$

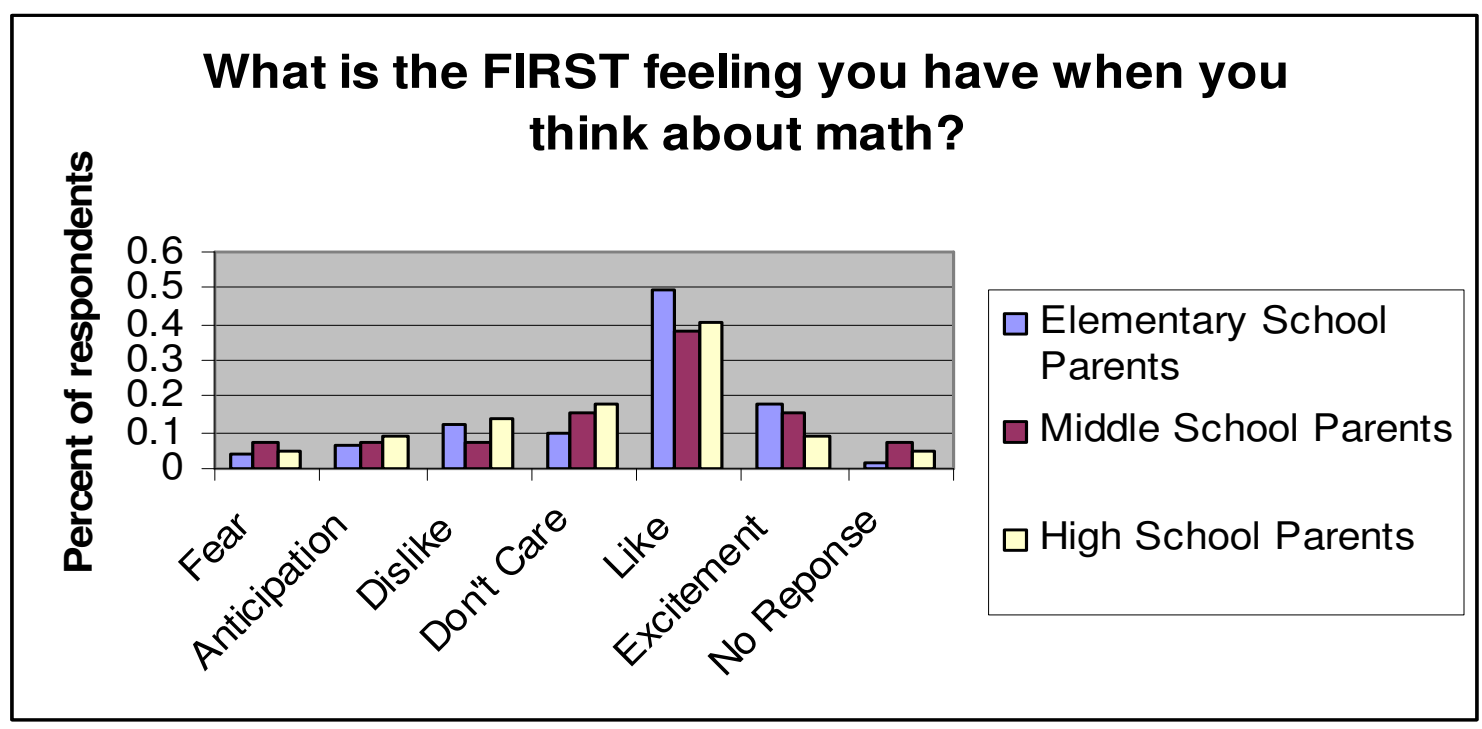

In the program's daily operation, which results in fellows working thousands of hours in classrooms each year (they are assigned to the same teacher and students for the year), we began to notice issues during out of school tutoring sessions. The sessions, first intended to be a 'homework helping' time, have evolved into activities, games and exercises that reinforced basic skills. For example, some fellows tutoring at an elementary school noticed when they were working with fifth graders on percentages, that it was, in fact fractions that the students were struggling with, so making the leap in understanding that percentages are an alternative way of expressing a fraction was not occurring. As program personnel continued to work with students, the tutoring sessions became times of reviewing and reinforcing basic skills such as operations, measurement, geometric shape, perimeter and area, fractions, etc. The students being tutored were much more comfortable after basic skills became rote to them. In today's elementary 
classroom, "spiraling" curricula such as Math Trailblazers (in use in our county) cover the basic skills, but, if a child misses a part of the "spiral," they could find themselves at a disadvantage when applying the concept later.

This need to reinforce basic skills, combined with the parents' expressed concerns about their ability to help their children, resulted in our plan to develop and implement both an elementary and a middle school family math event. The elementary version was first implemented in October 2005 at a local rural elementary school which is not a part of the RAMP-UP project. The event, coordinated by the project director and a teacher using the event as a part of her National Board Certification application, drew over 400 people. The principal said it was the most well-attended event during the school's history. Through the rest of the year, RAMP-UP sponsored and implemented seven additional elementary math events, including one each at our partner schools. In addition, the program held three community math events at churches or community centers in low income areas. Finally, the initial middle school version of the event made its debut in February 2007. The middle school program featured not only curriculum related activities for parents and students to do together, but a parent seminar on "The Math Path through High School." Nearly 150 parents and students attended, a much higher number than the school had originally estimated. In fact, one of the interesting challenges in the implementation was the general negativity from the middle school teachers about parental interest in such an event. Parent evaluations were overwhelmingly positive. The second middle school Family Math Night will be held at the end of March with a similar format, but adding a second parent seminar entitled "Teaching Financial Literacy to Teens", which is being developed by College of Management students under a sister GE Foundation grant.

\section{Family Math Night Content}

The Elementary Family Math Night kit is composed of five grade level specific activities tied to North Carolina curriculum competency goals in math for each grade K through 5 . The activities

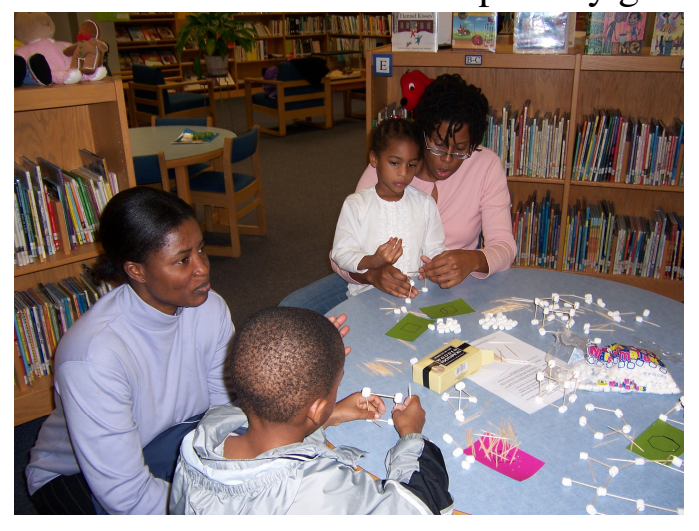
are a combination of some developed by other universities or educational institutions and adapted for our use, a few from books on math activities and many developed as a part of the RAMP-UP program and used in our classrooms. Many utilize science or engineering as the basis for the investigation into math application. For example, for third graders studying volume and measurement, one activity uses newborn diapers, turkey basters, measuring cups and tap water with yellow food color added. (Note: the 'yuk' factor cannot be underestimated with children!). The students are asked to compare the volume of liquid that can be contained by a newborn diaper, pitting a no-name vs. a name brand. The students pour water into the measuring cups and then use the turkey basters to add it to the open diaper. A data sheet is provided to keep track of the amount of water added to each. When the diapers are saturated and will absorb no more liquid, the amounts are totaled and a winner proclaimed. 
Other activities use dice or simple cards for games of reinforcement of math facts.

Geometry is explored in two and three dimensions using marshmallows and toothpicks. Straws and pipe cleaner creations aid in the study of perimeter and area. Measurement is addressed through many activities, from the 'paper clip height' activity in second grade, rice volume in third, body part measurement in fourth and angles in fifth grade. In fourth and fifth grade, the concepts of fractions and percentages are illustrated through tossing games and 'fishing' expeditions. Graphing is a

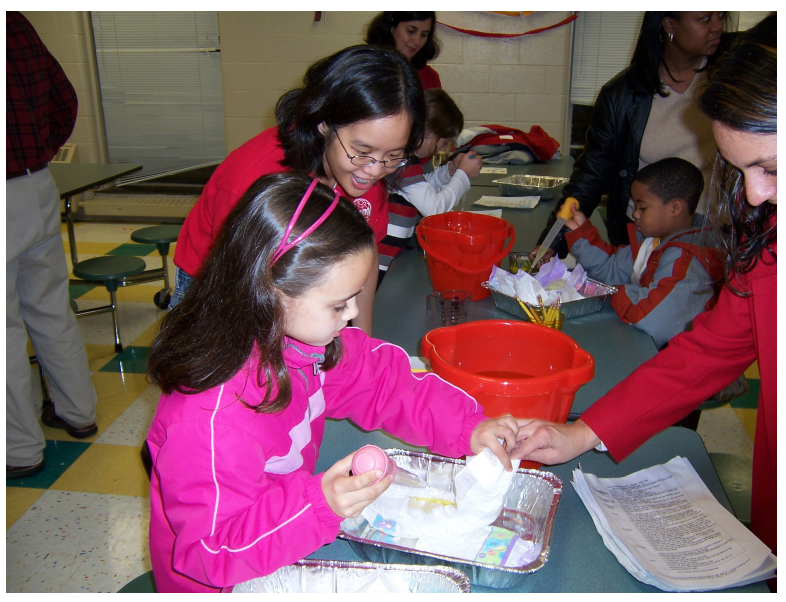
part of many activities, and grids are provided for data collection. All of the activities are intended for parents and children to work on together, so the parent leaves with some good ideas of how to work on these skills at home.

The curricular foci for these activities were chosen through analysis of classroom experiences of our undergraduate and graduate students and also through analysis of performance on our end of grade tests for elementary and middle school students. Performance data consistently show weaknesses in the areas of data collection and interpretation, measurement, graphing and geometry. ${ }^{6}$

The Elementary Math Night kit was assembled for less than \$200 and uses many common and inexpensive items. RAMP-UP students bring the kits to the schools, set up the materials, and then work with the students and parents at the stations to explain directions and provide guidance. Our fellows cite Math Nights as one of the most fun experiences of the program. Attendance by fellows assigned to any school other than the sponsoring one is voluntary, but at least half of our $40+$ fellows attend each one.

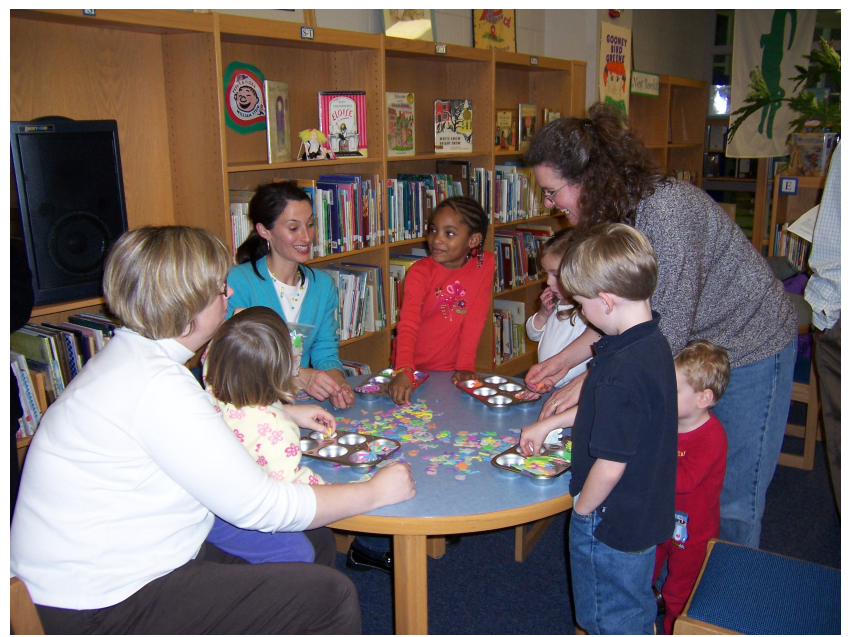

\section{Math night attendance and engagement}

Attendance at these events has been very good, although it is school dependent when it comes to advertising the event. We have discovered that when the PTA is notified of the event early, they will often assume the responsibility of getting the word out, because this is a topic of great interest to parents. In schools without an active PTA, where we relied on school staff to advertise, attendance was noticeably lower. Last year, RAMP-UP served over 3000 people through our school math nights. The four we have held this past fall averaged about 250 people per event. Surveys were given to parents at the last 
of the fall events, with a request that they return to the main area to turn in the survey at the end of the evening. The return rate was about $21 \%$. Overall, the program was rated very high by parents in terms of content and use of their time. Survey results are summarized in the table below.

Table 2: Math night parent survey results

\begin{tabular}{|c|c|}
\hline $\begin{array}{c}\text { Survey question } \\
\text { The activities presented were fun. }\end{array}$ & $\begin{array}{c}\text { Average response; } 1=\text { least agree, } 4=\text { most } \\
\text { agree }\end{array}$ \\
\hline $\begin{array}{c}\text { activities } \\
\text { I enjoyed working with my children on these } \\
\text { math }\end{array}$ & 3.68 \\
\hline I learned some new ways to help my child with \\
\hline $\begin{array}{c}\text { After doing these activities, I feel more } \\
\text { comfortable helping my child in math }\end{array}$ & 3.73 \\
\hline $\begin{array}{c}\text { I would attend another family math night at my } \\
\text { child's school }\end{array}$ & 3.54 \\
\hline $\begin{array}{c}\text { I would be interested in attending additional } \\
\text { family events on science and/or engineering }\end{array}$ & 3.88 \\
\hline When I was a child, I liked math & 3.68 \\
\hline $\begin{array}{c}\text { I have always been good at math } \\
\text { math be more comfortable attending a family } \\
\text { center at local church or community }\end{array}$ & 3.20 \\
\hline
\end{tabular}

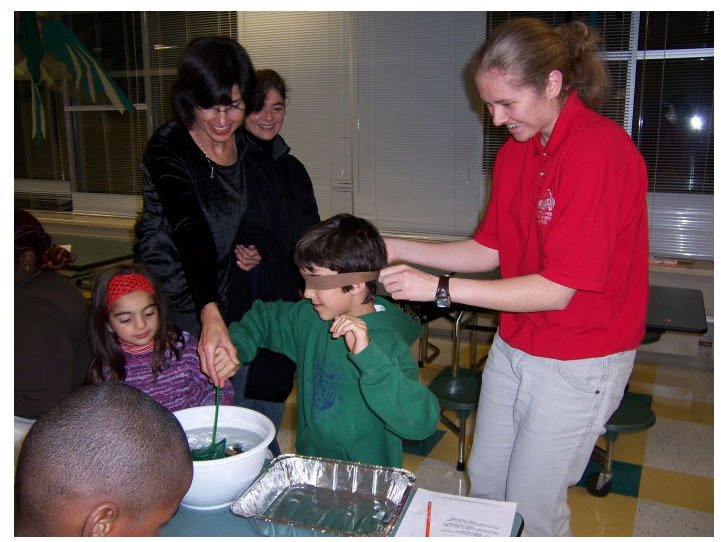

Of the parents who responded that they would be more comfortable attending a family math night at a local church, $53 \%$ were from an ethnic minority group. Forty-two percent of attending parents were from an ethnic minority group.

Parents were greeted by a welcome letter that contained tips and resources for working with children at home. (see Figure 4)

Figure 4: Excerpt from project director's parent welcome letter for math night events "As a parent, just by being here you're doing a great thing for your child. There are other resources here tonight you may take home that will give you more ideas how to help your child achieve academic success. Here are a few key points to remember:

1. If you don't know, say so. Not knowing is okay-it provides an opportunity for you to model how to ask for help and research and/or get the information. It is a powerful thing for an adult to say to a child, "I don't know but let's find out." This lets them know its okay to not know everything - we parents sometimes have a hard time with that one $:$. .

2. Share your own learning difficulties with your child. When I was young, I was very slow at learning math and thought I was stupid. I now know I need to DO math to understand it-not dumb just different. Children's learning styles vary; if your child is struggling ask for help from the school about ways to help them learn the material in a different way. Remember, teachers WANT your child to succeed! 
3. Finally, at the end of the day when homework is running late it is very tempting to just provide the answer. It works for that day, but doesn't help your child in the long run. Take a few minutes to remind your child of some ways to try to solve the problem, such as working backwards, drawing a picture, guessing and checking possible answers, making a table or looking for patterns. This is a long term way to help."

\section{Community Math events}

The inclusion of parents of underrepresented students has long been a challenge for schools. ${ }^{5}$ Despite increased and more intense efforts by school personnel, there remains wariness from these parents that it is hard to overcome. In some cases the parents' own experience in school and/or math class was unpleasant. There are cultural and socioeconomic barriers as well. Some parents must work during times that school events are held. Some parents view authority figures with distrust. With this in mind last May, the RAMP-UP project used a small grant from the William and Ida Friday Institute for Education Innovation to develop and implement a Community Math event at a local church.

The pastor of an African Methodist Episcopal church in a middle to lower middle class neighborhood offered his

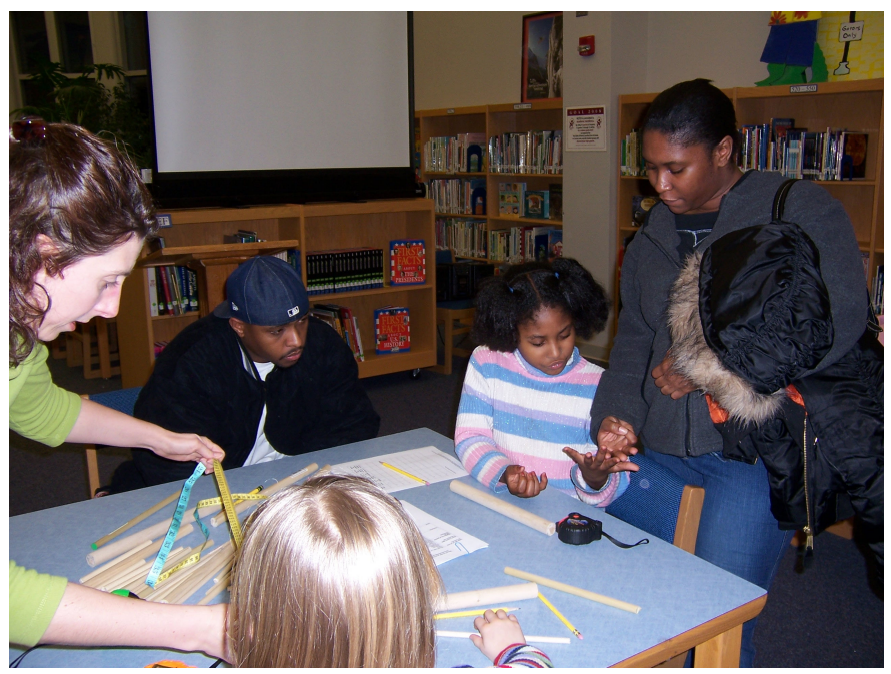
facility for the program. The parents and students from a nearby school with a high number of students on the federal free and reduced lunch program (an accepted indicator of poverty and directly correlated to high academic need) were invited to the event. The event was publicized using school flyers with classroom contests for the highest attendance rate, the school's automated messaging service and the church's own bulletins and after school program literature. Ten minutes before the official start time of 6 p.m., there was already a line of parents and children at the door. The event lasted two hours and attendance was estimated about 200 people, coming in a steady stream throughout.

Parents and children worked through activities together, and a few small door prizes were given away. The tables were staffed by RAMP-UP college students paired with local high school students earning service extra credit from their teacher, who was a parishioner. Each parent took home a plastic bag with dice, cards and directions on how to use them for math reinforcement, as well as a color booklet that compiled information from many respected sources on helping their children with math as well as how to be a strong advocate for your child when it comes to math placement. (This booklet is available for use by anyone who requests one.) Figure 5 shows an excerpt from the booklet. The school's principal and PTA president attended and commented that the parents who attended, who were approximately 90\% African American, were not ones who normally came to events at the school. 
Figure 5: Excerpt from parent Math Night booklet

\section{Why me? Well, parents are their child's most important teacher \\ Parents can help their children succeed in math by:}

(e) Talking with them about what they learned in math that day;

(C) Showing them examples of math in daily life (the grocery store and gas station are just a couple of examples);

Working with them at home on fun and interesting math activities;

(C) Encouraging your child to ask questions, solve problems and to explain their answers. Don't be afraid to say "I don't know but let's figure it out" to your child;

(e) Making them aware of when you are using math (such as figuring out how much money to give a clerk and how much change you get back); if it's difficult for you, admit it and then model determination by working it out.

(C) Challenging your child in their areas of math strength and getting support for them in their areas of math weaknesses, and seeking help from teachers and others if you are having trouble with it too;

(e) Being your child's BIGGEST math advocate! Stay aware of their progress in math and be sure they are on the right track.

Parents and students were surveyed. Forty-five student and twenty-two parent surveys were returned. The majority of parent surveys were from parents who were not parishioners of the church, so therefore were parents at the school attracted by the advertisement strategy. All of the parents said they would attend other events such as this, and just over $50 \%$ said they were more comfortable attending an academic event at a church rather than at the school. The parents who reported going to their child's school very infrequently (1 time per year or never) were most likely to write comments on the survey. One said "THANK YOU so much for offering this event. I greatly appreciate it." Other comments included from "I LOVE IT! Please come again."; "It was very nice to see students involved!" and "This was very helpful and fun."

The student surveys were similarly positive. All of the students said they had fun, that they'd like to come to another math night, and that they would do the activities at home with their families. The opinion on the best activity varied, but the large majority of the student participants answered "nothing" to the question of "What did you NOT like tonight?" Since this event, two smaller events were held at a church and a community center in a nearby lowerincome town, drawing again parents and students primarily from underrepresented groups. 


\section{Conclusion}

Family Math events are but one strategy to increase awareness of the fact that mathematics is in use everyday in many ways. In our research, parents have expressed trepidation about being able to help their children as they progress through increasingly rigorous math courses. The Family Math night provides parents with strategies and activities to not only help their children through new specific topics, but also to reinforce basic skills that will be used throughout school and life.

Some new areas of further exploration have arisen as a result of this endeavor. For example, the majority $(76 \%)$ of parents who returned school surveys were female. The potential correlation between a decreased comfort level in helping children in middle and high school math and the fact that some studies target this same timeframe in a girl's education as one of growing underachievement and disinterest in math is intriguing. Also, the majority of respondents report positive ("like", "excitement") first feelings when thinking of math yet the under-representation of females in STEM is well documented. Further study is warranted to explore these dichotomies.

The long-term influence of single event attendance is hard to measure but in our opinion lies more in the realm of building positive attitude vs. significantly impacting end of year test results. However, if parents take the materials and suggestions provided and apply them regularly at home, such impact could be seen by that student. The number of parents who attend math night events with their children and the highly positive response is a definite indicator for the success of such programs. Clearly, parents of all ethnicities and economic status are interested in finding ways to help their children become math achievers and problem solvers. Creative venues linking school to communities, working with parent organizations such as PTAs and involving the faith community have tremendous potential for increasing parent/school communication and parent/child interaction in math and in school in general.

Bibliography

1-Gagnon, George Jr., "Healing Math Learners," New Horizons for Learning Journal, http://www.newhorizons.org/trans/gagnon.htm, 2006.

2-Plato, The Republic, 360 BC.

3-Secada, W. G., "Teaching Mathematics to Dual Language Students," presented at the conference on Education of Language Minorities: the Teaching of Language and Mathematics at Aristotle University of Thessaloniki, Greece, May 2001.

4-Learning Point Associates, North Central Regional Educational Library, http://www.ncrel.org/sclrs/areas/issues/content/cntareas/math/ma8refer.htm.

5-Franklin, J. "Unlocking Mathematics for Minority Students.” Curriculum update. Association for Supervision and Curriculum Development, http://www.ascd.org, 2003.

6-2005 National Assessment of Educational Progress Report (NAPE) for North Carolina Mathematics Assessment, Public Schools of North Carolina, October 2005. 